\title{
Investigation of Dispersion Stability of Conductive Nano Ink Using 1-Octanethiol Coated Copper Nano Powders
}

\author{
Danee Cho, Jong-Hwan Baik*, Joong-Hark Park**, and Caroline Sunyong Lee ${ }^{\dagger}$ \\ Department of Materials Engineering, Hanyang University, Ansan 426-791, Korea \\ *Lean on Tech. Guri 471-854, Korea \\ **Nano Technology Inc, Daejeon 306-801, Korea \\ (Received July 30, 2012; Revised September 24, 2012; Accepted September 27, 2012)
}

\section{1-Octanethiol이 코팅된 나노 구리 분말을 이용한 나노 잉크의 분산도에 대한 연구 \\ 조단이 · 백종환* · 박중학** · 이선영 ${ }^{\dagger}$ \\ 한양대학교 재료공학과 \\ *Lean on Tech \\ **(주) 나노 기술 \\ (2012년 7월 30일 접수 ; 2012년 9월 24일 수정 ; 2012년 9월 27일 채택)}

\begin{abstract}
Copper nano particles have been considered as the materials for conductive ink due to its good thermal, electrical conductivity and low cost. However, copper nanoparticles oxidize easily, decreasing dispersion stability and electrical conductivity. Therefore, it is important to develop a method to minimize oxidation of copper nano particles to improve its dispersion stability property in copper nano ink. In this study, copper nano particles were coated with 1-Octanethiol VSAM(Vaporized Self Assembled Multilayers) to prevent oxidation and coated copper powders were dispersed in conductive ink successfully by studying its relationship of different chain length of solvents to 1-Octanethiol coating layer to fabricate nano ink. Various alcohol solvents, such as 1-Hexanol, 1-Octanol, and 1-Decanol were used. The coating layer was observed using FESEM and TEM. Furthermore, dispersion of copper nano particles in nano inks, was characterized using Turbiscan analyzer, viscometer, and contact angle measurement tool.
\end{abstract}

Key words: 1-Octanethiol, Cu, Dispersion, Conductive ink, Inkjet printing

\section{1. 서 론}

구리는 저렴한 가격과 우수한 열전도성, 전기 전도도를 가진 물질로서 Microelectronic 분야에서 점차 그 중요성 이 커지고 있는 물질 중에 하나이다. 최근에는 구리의 우 수한 물성을 Screen printing, Nano-imprinting, Roll-toRoll 그리고 Inkjet Printing(IJP) 등의 기술에 적용하여 가 격절감 및 기존 소재 대비 성능향상을 위한 목적으로 연 구가 진행되고 있다. ${ }^{1-5)}$ 이 중 Inkjet Printing(IJP) 기술은 경제적, 기술적으로 우수한 공정으로서 저렴한 공정비용 및 저온에서 공정이 가능한 기능성 잉크소재들의 개발을 통해 유연 전자소자(flexible electronics) 기술로의 적용이 큰 장점으로 대두 되고 있다 ${ }^{6}$. 기존의 전도성 잉크소재로

\footnotetext{
${ }^{\dagger}$ Corresponding author : Caroline Sunyong Lee E-mail : sunyonglee@hanyang.ac.kr

Tel : +82-31-400-5221 Fax : +82-31-436-8146
}

는 전도성이 우수한 $\mathrm{Ag}$ 가 가장 많이 사용되고 있으나 비 싼 가격으로 인해 상대적으로 저렴하고 우수한 물성을 가 진 구리로 대체하기 위한 연구가 진행되고 있다. 그러나 구리는 자체적인 Passivation layer를 형성하지 못하므로 대기 노출 시 $\mathrm{Cu}_{2} \mathrm{O}$ 혹은 $\mathrm{CuO}$ 로 쉽게 산화되는 단점이 존재 한다 ${ }^{7,8)}$. 특히 저온 공정을 위해 나노 크기의 구리입 자를 이용하게 되면 산화에 더욱 취약할 뿐만 아니라 잉 크로 제작 시 분산안정성이 떨어지는 문제가 발생하므로 잉크소재로서 적용하는 것에 한계가 존재한다. 이를 해결 하기 위해서 Spray coating, Dip coating, 자기조립박막 (Self-Assembled Monolayer, SAM) 등이 연구되고 있는데, $\mathrm{SAM}$ 의 경우 비교적 공정이 간단하고 공정조건에 따라 코팅막 두께의 조절이 용이하다. 자기 조립 박막으로 Alkanethiol $\left(\mathrm{CH}_{2}\left(\mathrm{CH}_{3}\right) \mathrm{nSH}\right)$ 계열의 물질이 주로 사용되고 있 다. Alkanethiol 물질중의 하나인 1-Octanethiol $\left(\mathrm{CH}_{2}\left(\mathrm{CH}_{3}\right)_{7} \mathrm{SH}\right)$ 은 말 단의 $\mathrm{S}$ 가 산화 되지 않은 순수한 금속표면과 공유결합을 통해 금속표면에 자기조립박막을 형성한다. 이러한 원리로 
구리 표면에 1-Octanethiol 코팅막을 형성할 경우 $\mathrm{Cu}-\mathrm{S}$ 결 합은 일정 기간 동안 구리 분말의 산화를 방지할 수 있 다 ${ }^{9,10)}$. 형성된 1-Octanethiol 자기조립 코팅막은 오존과 산 소를 투과시킬 수 있는 구조이기 때문에 영구적이지는 못 하다 ${ }^{11)}$. 일반적으로 습식 공정을 통해서 자기조립박막을 형성하지만 본 연구에서는 건식 코팅 방법을 이용하여 구 리 표면에 자기조립 코팅막을 형성하였다. Alkanethiol계 열은 Alchol계열의 물질과 유사한 분자구조를 가지나 사 슬의 길이와 말단의 결합각 차이로 인해 Alchol계열에 비 해 상대적으로 약한 dipole moment를 가진다. 따라서 Alkanethiol계열과 Alchol계열의 구조적 차이에 의한 특성 이 전도성 잉크로 제조 시 분산에 영향을 줄 것으로 판 단하였다. 따라서 본 연구에서는 Polyol method를 이용하 여 만든 $100 \mathrm{~nm}$ 사이즈의 구리 파우더 표면에 산화 방지를 위한 1-octanethiol VASM 코팅막을 형성하여, 1-Octanethiol 코팅막과 용매와의 관계가 분산도에 미치는 영향을 확인 하고자 하였다. 잉크의 용매는 Alchol계열 중에서도 1Octanthiol $\left(\mathrm{CH}_{2}\left(\mathrm{CH}_{3}\right)_{7} \mathrm{SH}\right)$ 의 체인 길이보다 짧은 $1-\mathrm{Hexanol}$ $\left(\mathrm{CH}_{3}\left(\mathrm{CH}_{2}\right)_{5} \mathrm{OH}\right), 1-\mathrm{Octanthiol}$ 과 체인 길이가 비슷한 1Octanol $\left(\mathrm{CH}_{3}\left(\mathrm{CH}_{2}\right)_{7} \mathrm{OH}\right)$, 1-Octanthiol보다 체인 길이가 긴 1-Decanol $\left(\mathrm{CH}_{3}\left(\mathrm{CH}_{2}\right)_{10} \mathrm{OH}\right)$ 을 선택하였다. 구리 파우더의 형상은 $\mathrm{SEM}$ 을 통해 분석하였다. TEM과 XPS 분석을 통 해 구리 표면의 1-Octanethiol 코팅막의 형성 유무를 확인 하고 산화방지막 특성을 가짐을 입증하였다. 1-Octanethiol 코 팅막과 용매의 관계에 의한 분산안정성은 Turbiscan 분석, 점 도 측정 및 contact angle의 분석을 통해서 확인하였다.

\section{2. 실험방법}

\subsection{1-Octanethiol 산화방지막 코팅 및 전도성 잉크 제조}

Polyol method를 이용하여 $100 \mathrm{~nm}$ 크기의 구리 나노 분
말을 합성하였다. 합성된 구리 표면의 $\mathrm{PVP}\left(\mathrm{C}_{6} \mathrm{H}_{9} \mathrm{NO}\right)$ 제 거를 위해 Washing 단계를 거쳐 상온에서 건조시켰다. PVP의 제거는 Table 1의 구리 표면 XPS 성분 정량 분석 평가를 통해 질소양이 최소화된 것을 통해 확인되었다. 구리의 산화방지를 위해 모든 과정은 $\mathrm{Ar}$ 분위기의 globe box내에서 진행하였다. 건조된 구리 파우더는 powder bottle 에 넣어 Fig. 1의 코팅 챔버에 장착한다. 본 연구에서 사 용된 코팅 챔버는 건식 기상 코팅 장비로서 진공 분위기 에서 기화점이 $200^{\circ} \mathrm{C}$ 이하인 유기재료를 기화시켜 나노 크기의 금속 분말의 표면에 $\mathrm{nm}$ 수준의 박막을 형성하는 장비이다. 이는 반도체 공정 과정에서 $\mathrm{PR}$ 과 실리콘의 접 합력을 좋게 하기 위해 사용 되는 Hexamethyl disilazane (HMDS)의 코팅 원리에 근거를 두고 설계 및 제작되었 다. ${ }^{12)}$ 본 코팅 장비는 코팅이 진행되는 진공 챔버, powder bottle, 1-Octanethiol 용액이 담겨있는 source bottle, 진공 펌프로 구성되어 있다. 코팅 과정은 다음과 같다. 진공챔 버와 source bottle 간의 기압차에 의해 source bottle에서 1-Octanethiol이 기화되어 진공챔버로 유입된다. 유입된 1Octanethiol이 powder bottle의 구리 표면에 코팅층을 형성 한다. 고진공 $\left(4.0 \times 10^{-6}\right.$ torr $)$ 분위기에서 코팅 공정 횟수의 조절을 통해 코팅층의 두께 조절이 가능하며 ${ }^{13)}$ 본 연구 에서는 5 분 6 회의 cycle을 선택하였다.

분산안정성 확인을 위해 잉크는 1-Octanethiol이 코팅된 구리 파우더를 이용하여 1-Hexanol, 1-Octanol, 1-Decanol 을 각각 용매로 사용하였고 $10 \mathrm{wt} \%$ 의 농도로 제조 하였 다. 초기 분산을 유도하기 위하여 15 분간 3 회 초음파 처 리를 하였다.

\section{2. 특성 평가}

Polyol method로 합성된 구리의 형상은 PVP를 제거한 후 SEM 분석 및 XPS 성분 분석을 통해서 확인 하였다.

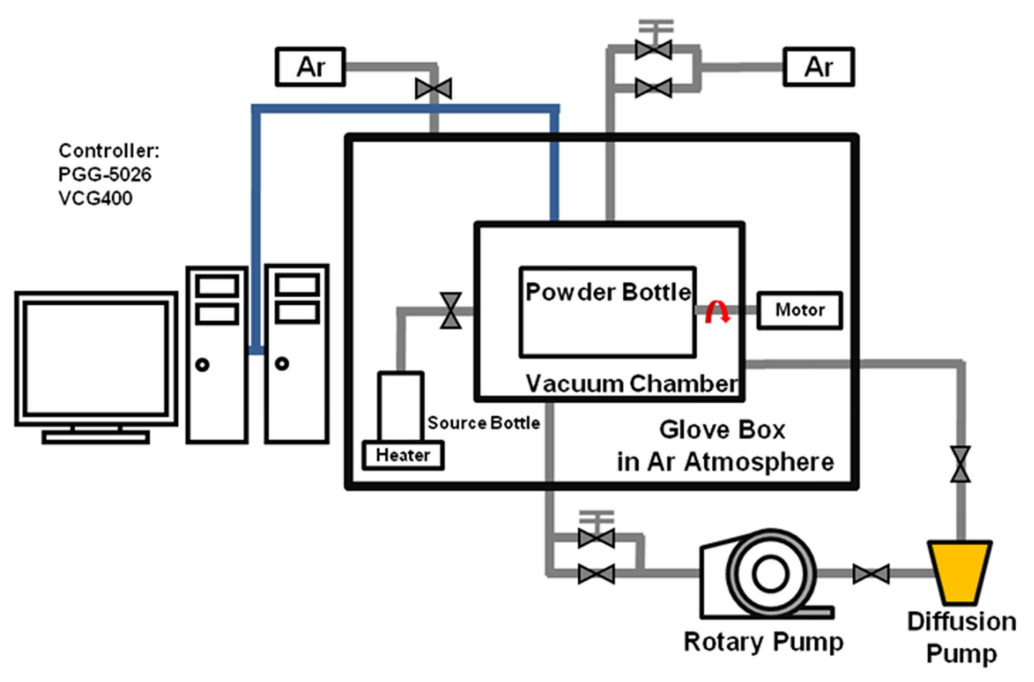

Fig. 1. Schematic of VSAM coating system. 
구리 표면의 1-Octanethiol 코팅막 형성은 TEM과 XPS를 통해서 분석하였다. 또한 이러한 구리표면의 1-Octanethiol 과 용매사이의 관계에의한 분산안정성 평가를 위해 $10 \mathrm{wt} \%$ 로 잉크를 제조한 뒤, 시간에 따른 잉크의 분산안정성 평 가를 위해 근적외선 투과 및 회절에 의한 분산안정성 측 정(Turbiscan lab, Formulation France)을 3일동안 1시간 간격으로 측정하였다. Turbiscan은 $880 \mathrm{~nm}$ 의 근적외선을 광원으로 사용하여 초기 광원을 $100 \%$ 로 놓고 transmission $(\mathrm{T}, \%)$ 값과 backscattering $(\mathrm{BS}, \%)$ 값을 측정하여 상대적 으로 용액 내부의 분산안정성의 변화를 시료의 높이에 따 라 측정하였다. 측정된 데이터는 시간의 흐름에 따라 축 적되어 분석이 가능하다. $\mathrm{T}$ 와 $\mathrm{BS}$ 는 용액의 입자 크기(d) 와 농도 $(\Phi)$ 의 영향을 받는다. 따라서 $\mathrm{BS}$ 값을 통해 역으 로 용액 내의 응집(입자의 크기 증가, aggregation)과 침강 (입자의 이동에 의한 농도변화, sedimentation)의 양상의 파 악이 가능하다. ${ }^{14)} \mathrm{BS}$ 는 입자의 사이즈가 $0.6 \mathrm{um}$ 일 때 최 대값을 가지므로 본 연구에서 제조한 잉크의 Turbiscan 결 과에서 $\mathrm{BS}$ 의 증가는 응집을 나타내고 감소는 침강을 나 타내는 것을 알 수 있다. 그리고 dilute한 용액이 아니기 때문에 $\mathrm{T}$ 값은 고려하지 않는다. Turbiscan 분석과 동시 에 점도 측정(LVDV-II $+\mathrm{PCP}$, Brookfield)과 contact angle 측정(Phoenix-300PLUS, Surface Electro Optics)을 진행 하였고 각각 3 일동안 3 회 시행하여 변화율을 관찰하 였다.

\section{3. 결과 및 고찰}

\subsection{1-Octanethiol 코팅막}

Polyol method로 합성된 구리 표면의 PVP를 벗겨낸 후 의 $\mathrm{SEM}$ 분석 결과 평균 $100 \mathrm{~nm}$ 사이즈의 구리 나노 파 우더가 형성됨을 확인하였다. XPS 분석의 질소 성분의 비율을 통해 구리 표면의 PVP가 대부분 제거됨을 확인 하였다(Table 1). Fig. 2에서 볼 수 있듯이 구리 파우더 표면의 1-Octanethiol 코팅막은 TEM 분석을 통해 확인한 결과 $10 \mathrm{~nm}$ 로 코팅층이 균일하게 형성된 것을 볼 수 있 다. 또한 XPS 결과(Fig. 3)를 통해 $162 \mathrm{eV}$ 의 $\mathrm{Cu}-\mathrm{S}$ 결합 이 형성되어 구리 파우더 표면에 1-Octanethiol 코팅층이 성공적으로 형성 됨을 확인할 수 있다. Table 1은 XPS 분석 결과를 나타낸 것이다. 이 결과를 통해 구리 표면 의 산소 농도가 최소인 것으로 확인되었다. 따라서 1Octanethiol 코팅막이 구리 표면에서 산화를 방지하는 것 을 확인하였다.

Table 1. Quantitative XPS Analysis of 1-Octanethiol Coated Copper Powders

\begin{tabular}{cccccc}
\hline XPS & $\mathrm{C}$ & $\mathrm{O}$ & $\mathrm{S}$ & $\mathrm{N}$ & $\mathrm{Cu}$ \\
$\mathrm{At} \%$ & 75.70 & 3.09 & 8.81 & 1.15 & 11.23 \\
\hline
\end{tabular}

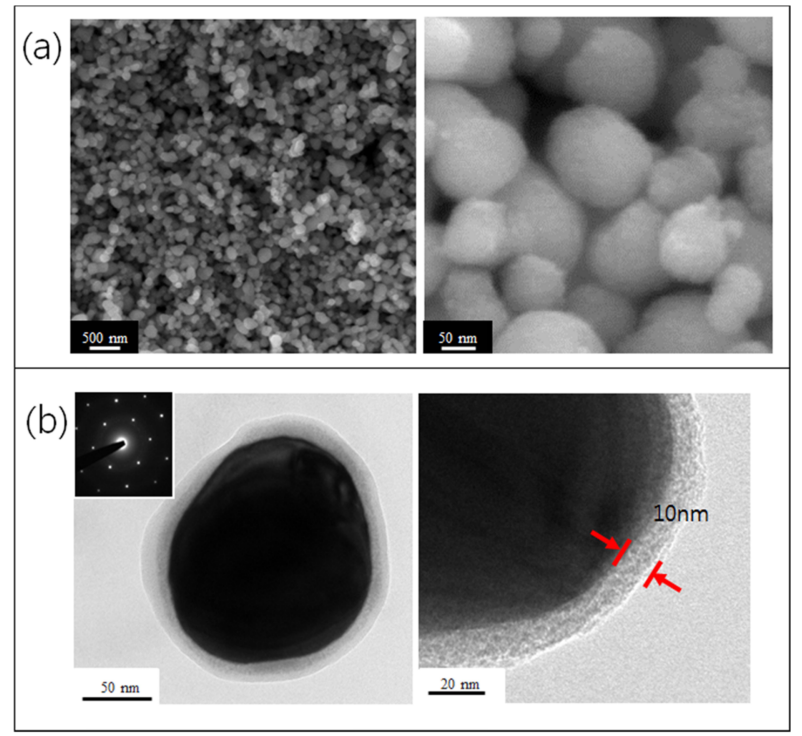

Fig. 2. (a) SEM image of copper powders fabricated by Polyol process, (b) TEM image of 1-Octanethiol coated copper nanoparticle.

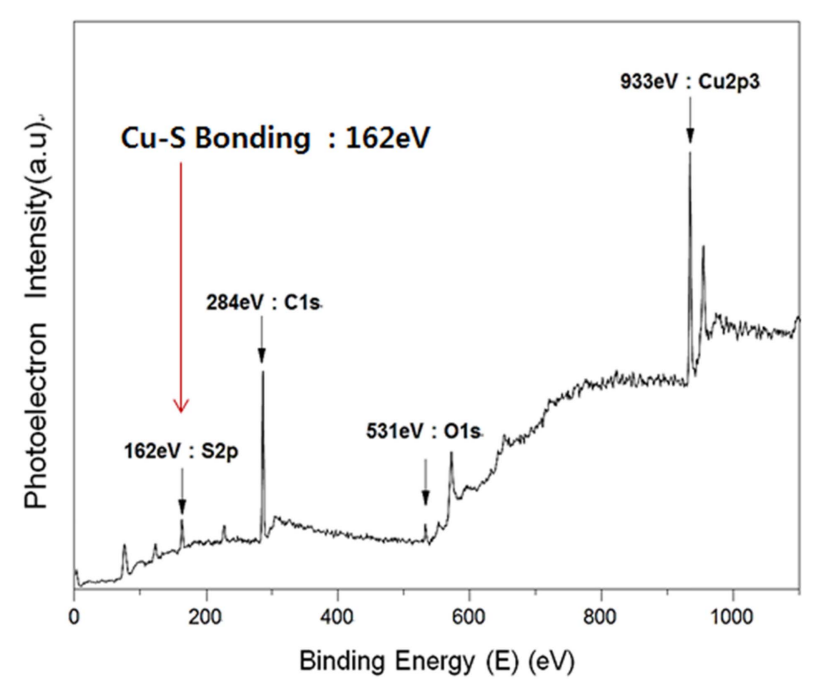

Fig. 3. Quantitative XPS analysis of 1-Octanethiol coated copper nanoparticles.

\section{2. 용매에 따른 분산안정성 평가}

\subsubsection{Turbiscan 분석}

Turbiscan 분석 결과는 $\mathrm{X}$ 축이 시료의 높이를 나타내고 $\mathrm{Y}$ 축이 상대적인 $\mathrm{BS}$ 값을 나타낸다(Fig. 4(a)). 초기 측정된 $\mathrm{BS}$ 값을 기준(zero)으로하여 상대적으로 측정된 $\mathrm{BS}$ 값 (reference mode)으로 분석하였다. 1-Octanethiol보다 체인 길이가 짧은 1-Hexanol 용매로 만든 잉크의 경우(Fig. 4(b)) Top에서 Middle까지의 $\mathrm{BS}$ 의 감소는 부분 밀도 감소에 의 해 이미 응집 된 입자 $(\mathrm{d}>0.6 \mathrm{um})$ 의 침강(sedimentation)이 진행되는 것을 의미한다. Middle에서의 변화폭이 좁은 것 은 Top에서 침강되는 입자들이 일정 농도를 유지시키기 때문이다. 확대된 모습을 보면 시료 높이에 따라 일정한 


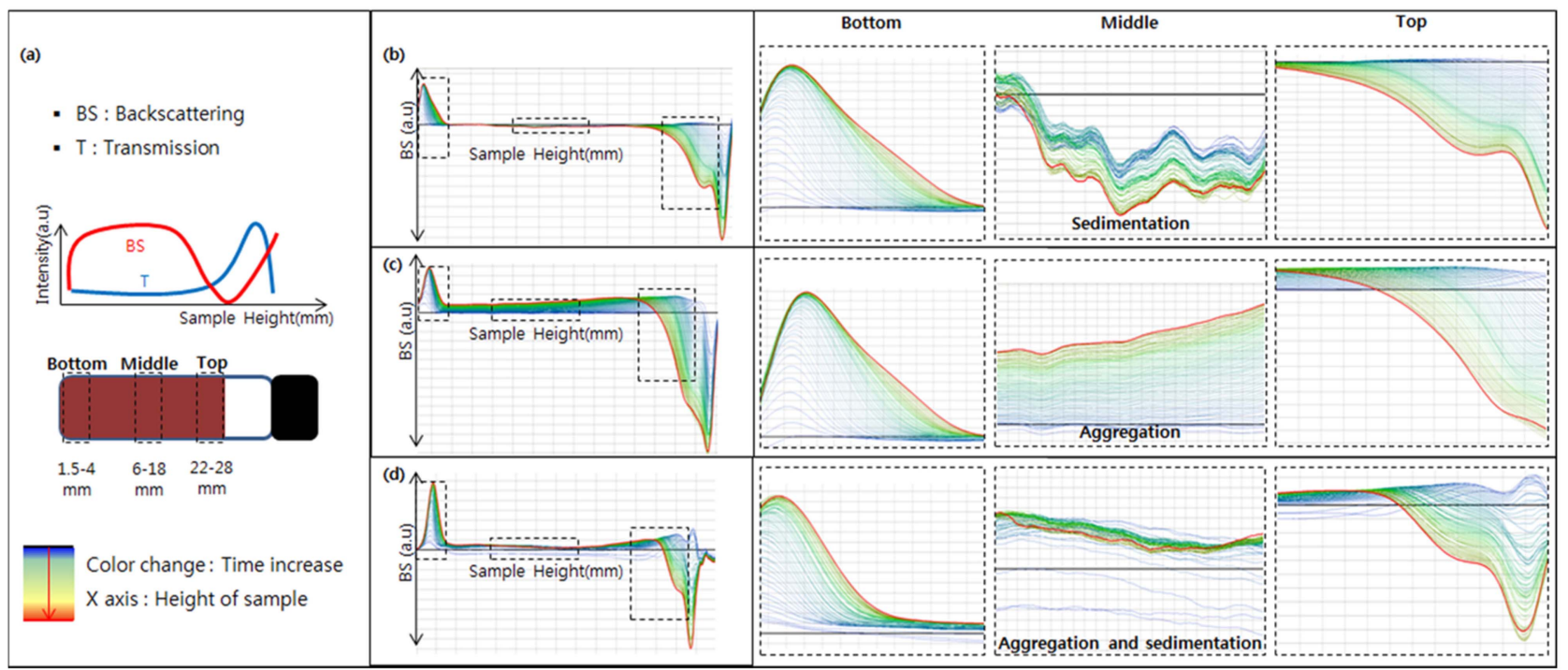

Fig. 4. Turbiscan analysis for dispersion stability of conductive nano ink using 1-Octanethiol coated copper nano particles in various solvents (a) schematic of Turbiscan analysis (b) 1-Hexanol based copper ink (c) 1-Octanol based copper ink (d) 1-Decanol based copper ink.

직선이 아닌 불안정한 곡선형태를 보이는 것을 확인할 수 있는데 이는 전 구간에서 매우 불안정한 상태임을 의미 한다. 따라서 1-Hexanol 용매 잉크의 경우 이미 초기에 빠 른 응집이 일어남과 동시에 전 범위에 걸쳐서 침강이 진 행되는 것을 알 수 있다. 이는 1-Hexanol 용매와 구리표 면의 1-Octanethiol 코팅막과의 관계가 매우 불안정하다는 것을 보여준다.

1-Octanethiol과 비슷한 체인길이를 가지는 1-Octanol 용 매 잉크의 경우(Fig. 4(c)) 전체적으로 $\mathrm{BS}$ 값이 증가하다가 Top 부분에서 $\mathrm{BS}$ 값이 감소 되는 것을 볼 수 있다. $\mathrm{BS}$ 의 증가는 $0.6 \mathrm{um}$ 이하 크기를 갖는 입자들의 응집에 의한 입자 크기 증가에 따른 결과이다. 따라서 전체적으로 입 자의 응집이 진행되고 있는 것을 알 수 있다. 1-Hexanol 용매 잉크에 비해서 middle 부분의 BS값이 안정적인 직 선형태로 증가하는 것으로 미뤄보아 안정적인 분산안정성 을 보이는 것을 확인할 수 있다. 전체적으로 구리 파우더 의 응집이 진행되고 있고 시간이 지남에 따라 Top 부분에 선 침강이 진행되어 $\mathrm{BS}$ 의 감소가 나타 나는 것을 확인할 수 있다. 이는 1-Octanol 잉크의 경우 1-Hexanol 잉크에 비 해 안정적인 분산안정성을 가진다는 것을 알 수 있다.

1-Octanethiol 보다 긴 체인길이를 가지는 1-Decanol 용 매 잉크의 경우(Fig. 4(d)) 전체적으로 $\mathrm{BS}$ 값이 증가하는 것처럼 보이나 Middle 부분을 보면 $\mathrm{BS}$ 값의 증감이 번갈 아 나타나는 것을 볼 수 있다. Top에선 초기 응집 후 점 차 침강되는 것을 볼 수 있으나 Middle은 응집과 동시에 침강이 일어나 불안정한 상태라고 볼 수 있다. 전체적으 로 라인의 모양은 1-Octanol ink와 유사하지만 내부 양상 은 $\mathrm{BS}$ 의 증감이 번갈아 나타나며 1-Hexanol 용매 잉크와 같이 매우 불안한 분산안정성을 보임을 확인할 수 있다.
전체적으로 모든 용매의 잉크에서 Bottom에서 $\mathrm{BS}$ 값 증가 는 침강에 의한 밀도 증가에 따른 결과로 공통된 양상을 보이지만 1-Hexanol잉크는 전체적으로 침강이 지배적으로 나타나므로 분산안정성이 가장 낮은 것을 확인할 수 있 다. 1-Hexanol 용매 잉크와 달리 1-Octanol 용매 잉크와 1-Decanol 용매 잉크는 middle 부분에서 응집이 일어나고 Top에서 응집이 진행되다가 점차 침강이 진행되는 비슷 한 양상을 보인다. 그러나 Middle에서 측정된 $\mathrm{BS}$ 그래프 는 매우 다른 모습을 보인다. 따라서 1-Octanol 용매 잉크 와 1-Decanol 용매 잉크의 분산안정성의 차이점을 확인하 기 위해 Middle 부분의 안정성을 Fig. 5의 시간에 따른 $\mathrm{BS}$ 값의 변화값 $(\mathrm{BSS})$ 그래프로 살펴보았다. 1-Octanol 용 매 잉크의 경우 전체적으로 안정적인 응집이 진행되기 때 문에(Fig. 5(a)) $\Delta \mathrm{BS}$ 값이 일정하게 증가하는 선형 변화를 보이는 반면에 1-Decanol 용매 잉크의 경우(Fig. 5(b)) 시 간에 따라 $\Delta \mathrm{BS}$ 값의 증감이 반목되는 매우 불안정한 모 습을 볼 수 있다. 따라서 1-Octanethiol의 체인길이와 비 슷한 체인 길이를 가지는 1 -Octanol 용매 잉크가 가장 안 정적인 분산안정도를 가지는 것을 확인하였다. 이러한 결 과로 보아 구리에 코팅된 octanethiol의 체인 길이와 코팅 된 구리 분말이 분산되는 용매의 체인 길이가 절대적으 로 영향을 미친다는 것을 알 수 있다. 위의 결과에서 보 여 주듯이 분말이 용액상의 안정적인 분산을 위해서는 용 액의 chain 길이가 코팅 막의 chain 길이가 같아 입자간 의 완벽한 척력 작용을 이용하여 분산이 최대화 되는 것 을 알 수 있다. 코팅 막의 chain 길이와 용매의 chain 길 이가 같지 않을 경우 코팅된 분말간의 척력이 최소화되 어 분산이 제대로 안 이루어지고 이것이 점도에도 영향 을 미치는 것을 알 수 있다. 


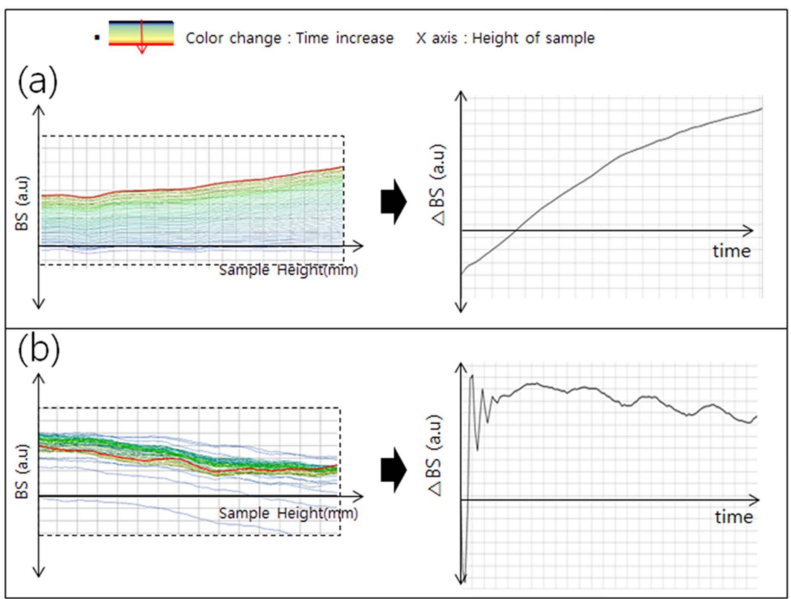

Fig. 5. Turbiscan analysis in the Middle $(6 \sim 19 \mathrm{~mm})$ portion of samples for (a) BS and $\triangle B S$ analysis of 1-Octanol based copper ink, and (b) BS and $\triangle B S$ analysis of 1Decanol based copper ink.

\subsection{2. 점도 분석}

Table 2에서 볼 수 있듯이 3일동안 잉크의 점도 변화를 분석한 결과 1-Hexanol이 가장 점도 변화 폭이 큰 것을 확인할 수 있다. 초기 점도 $7.8 \mathrm{cp}$ 에서 3일만에 1-Hexanol 용매 본래의 점도 값인 $4.3 \mathrm{cp}$ 에 가까운 $4.7 \mathrm{cp}$ 까지 떨어 진 것을 확인할 수 있다. 이는 turbiscan 분석결과와 유사 한 의미를 갖는다. Turbiscan 분석에서 1-Hexanol 용매 잉 크의 경우 전체적으로 침강이 매우 빠르게 진행되는 모 습을 보였다. 즉 초기 1-Hexanol 용매 잉크의 점도 보다 3 일 후의 점도 값이 큰 폭으로 떨어진 것은 잉크 전체적 으로 파우더의 침강이 일어나면서 발생하는 현상으로 볼 수 있다. 1-Octanol 용매 잉크와 1-Decanol 용매 잉크의 경우 1- Hexanol 용매 잉크에 비해 상대적으로 적은 변화

Table 2. Time-dependent Viscosity Variation Result of $10 \mathrm{wt} \%$ Ink using 1-Octanethiol Coated Copper Nano Powders in Various Solvent

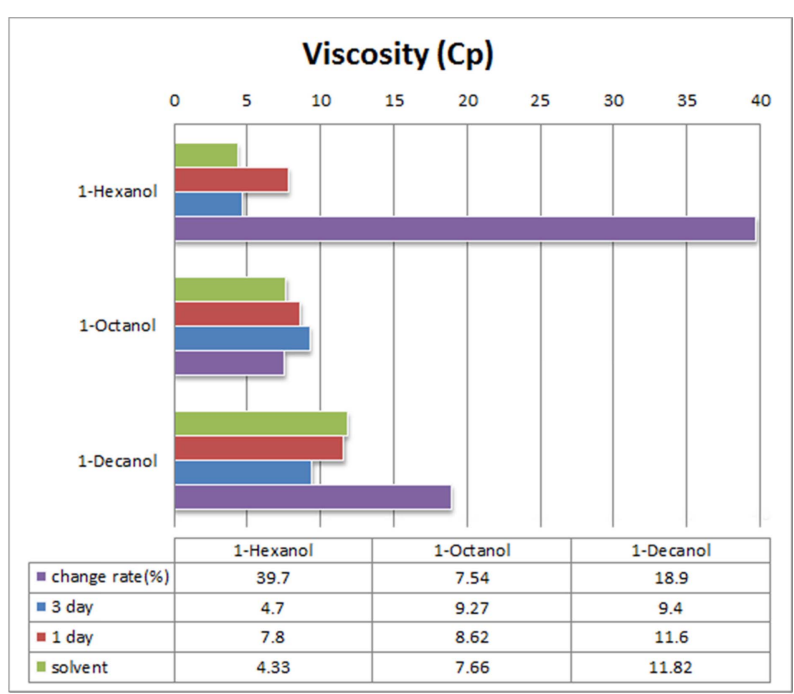

율을 보인다. 이는 Turbiscan 결과와 비슷한 양상을 보이 는 것으로 볼 수 있다. 상대적으로 1-Octanol 잉크의 점도 변화율이 가장 적은 것은 1-Decanol 용매 잉크 보다 안정 적인 분산안정성을 보이기 때문인 것으로 생각된다. 따라 서 3일간의 점도 변화율을 확인한 결과 1-Octanol 용매 잉 크가 가장 낮은 점도 변화율을 보이는 것을 확인하였다.

그러므로 위에서도 언급 되었 듯이 코팅된 분말의 분 산 작용이 용매의 chain 길이에 영향을 미쳐 코팅 막의 chain 길이와 용매의 chain 길이가 같을 경우 서로간의 척 력 작용으로 인해 시간에 따른 점도 변화율이 최소화된 것을 알 수 있다.

\subsubsection{Contact angle분석}

잉크의 분산안정성에 따른 점도 변화가 surface tension 에도 영향을 줄 것으로 판단하고 Contact angle의 시간에 따른 변화를 분석하였다. Contact angle 분석 결과를 살펴 보면 Turbiscan 분석과 점도 분석에서 보인 양상이 비슷 하게 나타나는 것을 확인할 수 있다. Table 3 에서 볼 수 있듯이 3일간 Contact angle의 변화율을 측정한 결과 1Octanol 용매 잉크의 변화율이 가장 작은 것을 확인할 수 있다.

그러므로 Turbiscan 분석, 점도 측정 및 contact angle 분석을 종합한 결과 1-Octanol 용매 잉크가 가장 안정적 인 분산도를 보이는 것을 확인하였다. 이는 구리 표면의 1-Octanethiol 코팅막의 체인길이와 비슷한 체인 길이를 가 지는 1-Octanol 용매가 잉크의 분산안정성을 유도하는데 가장 안정적인 특성을 가지는 것으로 분석되었다. 따라서 코팅막의 종류 따른 용매의 선택이 잉크의 분산안정성에 매우 중요한 영향을 미치는 것을 확인하였다.

\section{4. 결 론}

Polyol method를 이용하여 $100 \mathrm{~nm}$ 크기로 합성된 나노 구리 입자의 표면에 건식 코팅 공정을 통해1-Octanethiol

Table 3. Time-dependent Contact Angle Variation Result of $10 \mathrm{wt} \%$ Ink using 1-Octanethiol Coated Copper Nano Powders in Various Solvent

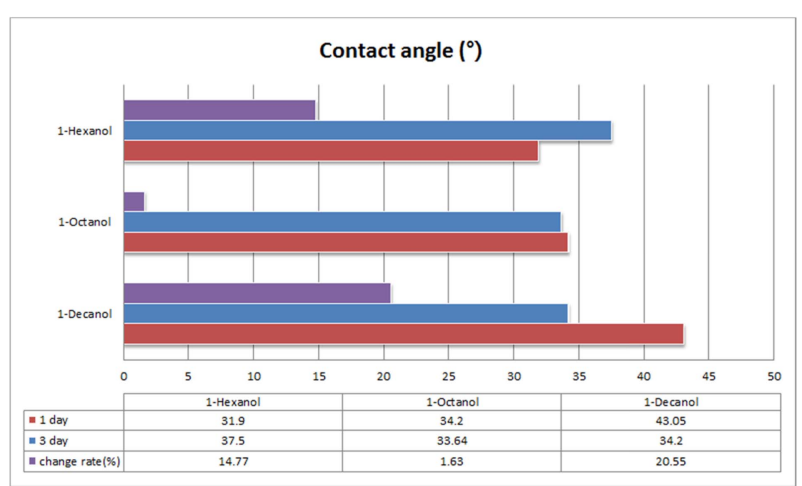


코팅막을 형성하였고 TEM 분석으로 $10 \mathrm{~nm}$ 두께로 형성 됨을 확인하였다. XPS 분석을 통해 $\mathrm{Cu}-\mathrm{S}$ 결합 peak을 확 인하였고 성공적으로 1-Octanethiol 코팅막이 형성된 것을 알 수 있었다. 또한 산화방지 효과 특성이 보임을 확인하 였다. Thiol 계열이 Alchohol과 비슷한 분자구조를 가지므 로 구리 표면에 코팅한 1-Octanethiol의 체인 길이와 Alchohol 계열의 용매의 체인길이에 의해서 잉크의 분산도 가 영향을 받을 것으로 판단하였다. 구리표면의 1-Octanethiol 코팅막의 체인길이와 Alchohol 계열 용매의 체인길이 차 이에 의한 분산안정성 평가를 위해서 1-Octanethiol이 코 팅된 구리 파우더로 제조한 잉크의 용매를 1-Hexanol, 1Octanol, 1-Decanl로 달리하여 Turbiscan, 점도측정 및 contact angle을 분석하였다. 구리 입자 표면 1-Octanethio 코팅막의 체인 길이와 비슷한 길이를 갖는 $1-$ Octanol 잉 크가 가장 안정된 분산 안정성을 보임을 확인하였다.

\section{Acknowledgment}

The present work was carried out with the support of a Next Generation New Technology Development Program (Project No. 10030038) of the Korea Ministry of Commerce, Industry and Energy (MOCIE) and this work was also supported by the National Research Foundation of Korea (NRF) grant funded by the Korea government (MEST) (No. 2011-0029862).

\section{REFERENCES}

1. B. K. Park, D. Kim, S. Jeong, J. Moon, and J. S. Kim, "Direct Writing of Copper Conductive Patterns by Ink-jet Printing," J. Thin Solid Films., 515 7706-11(2007).

2. T. Ito and S. Okazaki, "Pushing the Limits of Lityography,"
Nature., 406 1027-31 (2000).

3. K. salaita, Y. Wang, and C. A. Mirikin, "Applications of Dippen Nanolithography," Nat. Nanotechnol., 2 145-55 (2007).

4. T. Kawase, S. Moriya, C. J. Newsome, and T. Shimoda, "INkjet Printing of Polymeric Field-dffect Transistor and Its Application", JSAP, 44 3649-58 (2005).

5. J. Bharathan and Y. Yang, "Polymer Electroluminescent Devices Processed by Inkjet Printing," Appl. Phys. Lett., 72 2660-62 (1998).

6. I. K. You, J. B. Koo, Y. Y. Noh, and B. G. Yu, "Technology Trend of Printed Electronics(in Korean)," ETRI, 24 [6] 4151 (2009).

7. Y. S. Kim, S. K. Kim, and J. J. Kim, "Room Temperature Surface Passivation Method using thin Ag Layer at the Damascene Cu Structure," Theories and Applications of Chemical Engineering, 8 5210-13 (2002).

8. Y. Wang, P. Chen, and M. Liu, "Synthesis of Well-defined Copper Nanocubes by a One-pot Solution Process," Nat. Nanotechnol., 17 6000-6 (2006).

9. G. K. Jennings, J. C. Munro, T. H. Yong, and P. E. Laibinis, "Effect of Chain Length on the Protection of Copper by Nalkanethiols," Langmuir., 14 6130-39 (1998).

10. M. R. Seong, G. Y. Lee, D. K. Kim, Y. S. Kim, and C. S. Lee, "Octanethiol Coating of Nano-sized Copper Powders using the Vapor Self-assembled Monolayer Method," Met. Mater. Int., 15 963-66 (2009).

11. M. H. Schoenisch and J. E. Pemberton, "Air Stability of Alkanethiol Self-assembled Monolayers on Silver and Gold Surfaces," J. Am. Chem. Soc., 120 4502-13 (1998).

12. C. S. Lee, Y. B. Choi, M. R. Seong, G. Y. Lee, and J. Y. Choi, Korean Patent, 10-2008-0060198 (2008).

13. J. H. Kwon, S. Y. Park, Y. S. Kim, and C. S. Lee, "Controlled Thicknesses of Vaporized Self-Assembled Multilayers on Copper Nanopowders Under Ultra-High Vacuum (UHV)," Nat. Nanotechnol., 12 [2] 1206-10 (2012).

14. Quactachrome, Particle World 4, pp. 8 ed. by Dietmar Klank, Ton Goverde, 2010. 